TITLE:

\title{
Investigation of post-grafted groups of a porous coordination polymer and its proton conduction behavior.
}

\section{AUTHOR(S):}

Inukai, Munehiro; Horike, Satoshi; Umeyama, Daiki; Hijikata, Yuh; Kitagawa, Susumu

\section{CITATION:}

Inukai, Munehiro ... [et al]. Investigation of post-grafted groups of a porous coordination polymer and its proton conduction behavior.. Dalton transactions 2012, 41(43): 1326113263

\section{ISSUE DATE:}

2012-11-21

URL:

http://hdl.handle.net/2433/178732

\section{RIGHT:}

(c) The Royal Society of Chemistry 2012; この論文は出版社版でありませ ん。引用の際には出版社版をご確認ご利用ください。; This is not the published version. Please cite only the published version. 


\title{
Investigation of post-grafted groups of a porous coordination polymer and its proton conduction behavior
}

\author{
Munehiro Inukai, ${ }^{a}$ Satoshi Horike, ${ }^{b, c}$ Daiki Umeyama, ${ }^{b}$ Yuh Hijikata, ${ }^{b}$ and Susumu Kitagawa*a,b,c,d \\ Received (in $X X X, X X X)$ Xth $X X X X X X X X X 20 X X$, Accepted Xth $X X X X X X X X X 20 X X$ \\ 5 DOI: 10.1039/b000000x
}

We investigated the configuration of substituent groups that are post-synthetically bound to the pore surface in a porous coordination polymer. This study demonstrates the observations of orientation, coordination fashions of the ${ }_{10}$ grafted groups which contribute to approach the improved proton conductivity in porous frameworks.

Porous coordination polymers (PCPs) and metal organic frameworks (MOFs) have attracted considerable attention for a range of functions including separation, ${ }^{1}$ catalysis, ${ }^{2}$ and ion 15 conductivity. ${ }^{3}$ As a strategy for designing pore characteristics, the post-synthetic method (PSM), that is, the chemical modification of a framework after self-assembly, has been a powerful technique. ${ }^{2 \mathrm{a},} 45$ In general, it is hard to describe their crystallographic structures because post-grafted substituent 20 groups in pores have no crystallinity. Therefore studies on spectroscopic characterizations of modified PCPs have been limited except a few reports. ${ }^{6}$ For further development and systematic design of functional pores by PSM, spectroscopic characterization of the substituent groups is strongly required 25 because their configuration and mobility directly influence the properties in the micropores. For the characterization of inside pores, solid-state nuclear magnetic resonance (SSNMR) is a useful method that provides local structure and molecular mobility with disordering. So far, limited numbers of SSNMR 30 studies revealed the conformation of the guest molecule ${ }^{7}$ and the structure of the functional group in the pores of PCPs. ${ }^{8}$

Among the functions of PCPs, anhydrous proton conductivity has a great potential as a new type of ionic device such as solidstate electrolyte in fuel cell. Some previous reports described that 35 guest organic molecules such as imidazole or histamine were physically accommodated into the pores to generate proton conductivity in solids. ${ }^{9}$ For the development of proton conducting PCPs, not only an improvement of conductivity, but also the control of working temperature where conductivity exhibits is 40 important.

In this work, we demonstrate the post-synthetic modification of histamine on the micropore surface and elucidate the configuration of the histamine in the pores. SSNMR analyses reveal the chemical bonding and location of the histamine inside 45 the pores and we also show the capability of proton conductivity of the modified porous framework.

We selected $\left[\mathrm{Zn}_{2}(2,5-\mathrm{DOTP})\right]_{n} \quad($ DOTP $=2,5-$ dioxidoterephthalate, MOF-74 or CPO-27(Zn)) with a honeycomb analogous structure containing 1D straight 50 micropores of ca. $11 \AA$ diameter and coordinatively unsaturated metal sites (denoted as $\mathbf{1}$, Scheme 1). ${ }^{10}$ Because the metal of $\mathbf{1}$ plays the role of a Lewis acid site and $\mathbf{1}$ has high thermal and chemical stabilities, it is a suitable framework for PSM. As the post-grafted molecule, we employed histamine, which is also of ${ }_{55}$ interest for proton conductivity. ${ }^{9 \mathrm{a}}$ To coordinate histamine to the metal sites of $\mathbf{1}$, dehydrated $\mathbf{1}$ and histamine were immersed in toluene and refluxed. Then the microcrystalline material obtained was filtered and heated under vacuum to remove histamine located on the surface of the microcrystals and toluene (product 60 denoted 1-His). Powder X-ray diffraction patterns show that the crystal structure was retained during PSM, bulk histamine on the surface of crystal was removed by the heating treatment, and the packing of the histamine molecules has no cyratallinity (Fig. S1).

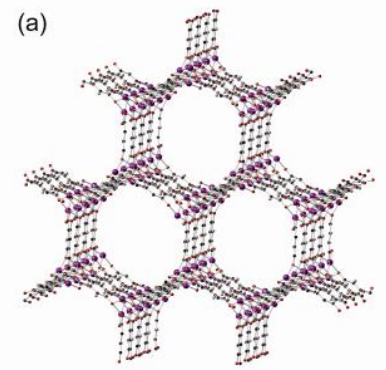

(b)

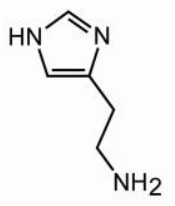

Scheme 1 (a) Crystal structure of $\left[\mathrm{Zn}_{2}(2,5 \text { dihydroxyterephthalic acid) }]_{n}\right.$ 65 (1), and (b) histamine.

An NMR spectrum of a solution of decomposed 1-His shows loaded histamine that amounts to 0.77 histamine per one $\mathrm{Zn}^{2+}$ and slight residual toluene (Fig. S2). The TGA profile of 1-His (Fig. S3) shows removal of histamine from the pores above $150{ }^{\circ} \mathrm{C}$, 70 which is clearly higher than the melting point of bulk histamine $\left(83{ }^{\circ} \mathrm{C}\right)$. Even when the temperature ramping rate decreases, the weight loss at $150{ }^{\circ} \mathrm{C}$ does not change, indicating that the accommodated histamine is stably bound to the pore surface.

To elucidate the local configuration of histamine in the pore, ${ }_{75} 2 \mathrm{D}{ }^{1} \mathrm{H}-{ }^{13} \mathrm{C}$ heteronuclear correlation (HETCOR), ${ }^{11}$ which highlights spatially adjacent species through ${ }^{1} \mathrm{H}-{ }^{13} \mathrm{C}$ dipoledipole interactions, ${ }^{7,}{ }^{12}$ was performed. Fig. 1 shows the ${ }^{1} \mathrm{H}$ and ${ }^{13} \mathrm{C}$ projection spectra and the ${ }^{1} \mathrm{H}-{ }^{13} \mathrm{C}$ correlation spectrum. In the projection spectra, all the peaks of the framework, histamine, and 80 toluene are observed. The ${ }^{1} \mathrm{H}-{ }^{13} \mathrm{C}$ correlation spectrum shows strong correlation peaks attributed to intra-/intermolecular 
interaction in the same molecular species. Weak intermolecular correlation peaks between the ${ }^{1} \mathrm{H}$ signal of the alkyl chain in histamine at $2.3 \mathrm{ppm}$ and the ${ }^{13} \mathrm{C}$ signals of DOTP at 124.1 and 124.4 ppm shown in Fig. 1b and 152.5 ppm shown in Fig. 1a are 5 observed. This indicates that the tail of the histamine molecule is located near the $\mathrm{Zn}^{2+}$ ions of 1-His, as shown in Fig. 2a. Interestingly, there are no intermolecular correlation peaks between the imidazole ring of histamine and DOTP. This suggests that the distance between the imidazole ring of 10 histamine and DOTP is larger than that between the alkyl chain of histamine and DOTP.

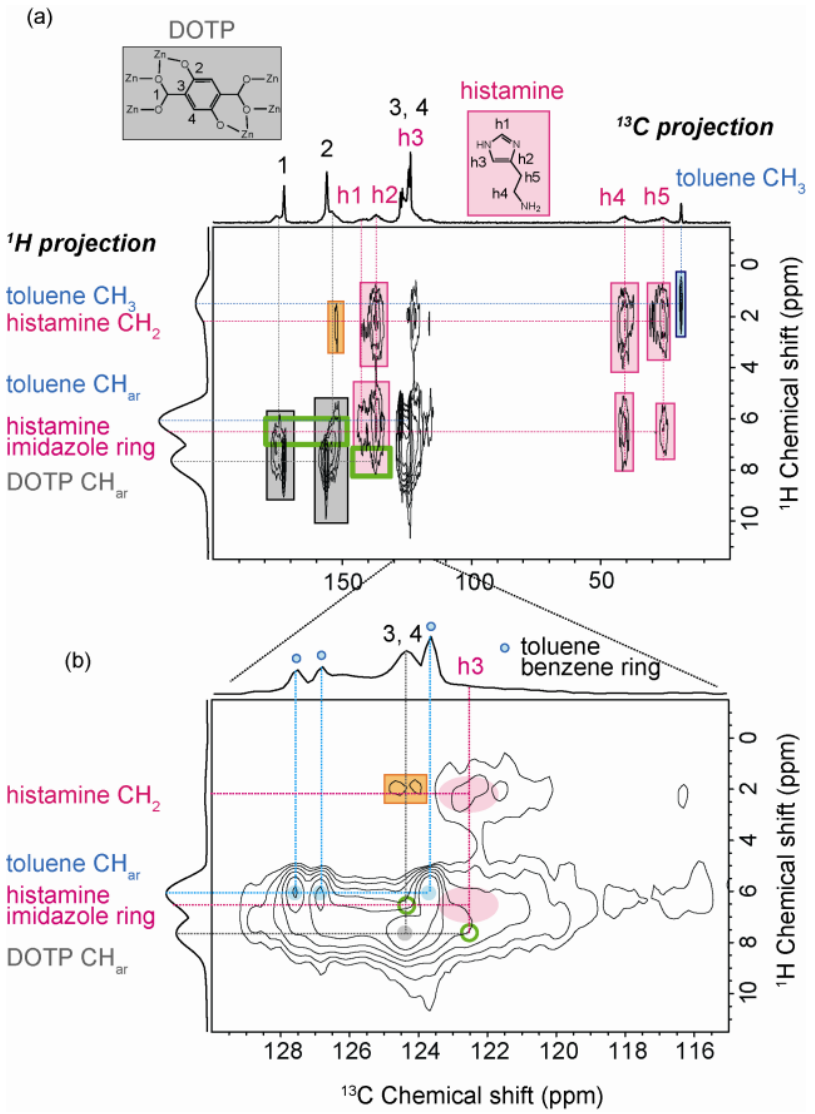

Fig. $12 \mathrm{D}{ }^{1} \mathrm{H}-{ }^{13} \mathrm{C}$ HETCOR spectra of 1-His. The expansion of the ${ }^{13} \mathrm{C}$ chemical shift region is shown in (b). Grey, pink, and blue boxes and circles represent correlation peaks of intra-/intermolecular interaction in 15 the DOTPs, histamines, and toluenes, respectively. Orange boxes represent intermolecular correlation peaks between the alkyl chain of histamine and DOTP. Green boxes and circles show no intermolecular correlation peak between the imidazole ring of histamine and DOTP.

From these HETCOR results, we propose that the imidazole 20 rings are located at the centre of the pore, as shown in Fig. 2a. There are six accessible metal sites in a cavity with the size of ca. $11 \times 11 \times 7 \AA^{3}$. Considering the size of histamine (ca. $110 \AA^{3}$ ), the imidazole rings are probably closely packed next to each other in the straight channels. To support the proposed 25 configuration of packed histamines, we carried out molecular dynamics calculations for the histamines. A typical calculated structure is shown in Fig. 2b; it supports the results of SSNMR regarding the direction of grafted histamine in the pores.

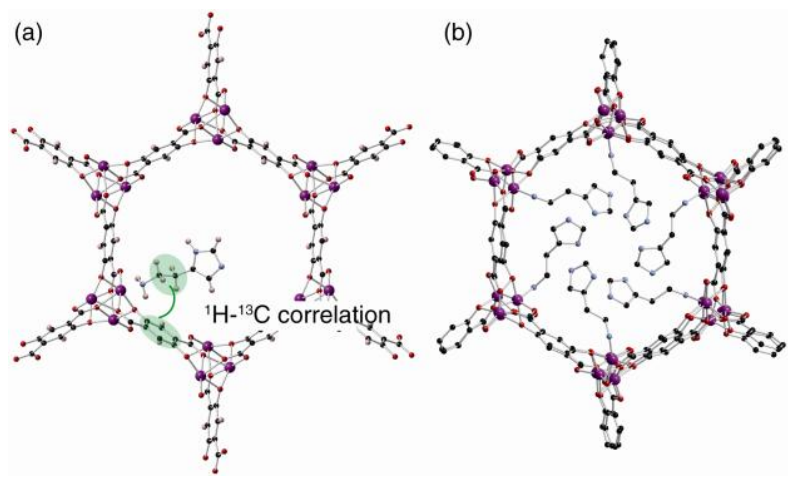

${ }_{30}$ Fig. 2 (a) Schematic representation of proximity between framework and histamine. (b) Typical simulated configuration of packed histamines in $\mathbf{1}$.

To evaluate the proton conductivity, we performed a.c. impedance measurements of 1-His under an $\mathrm{N}_{2}$ atmosphere. Fig. S4 shows the temperature dependence of proton conductivity. 35 The anhydrous conductivity of $\mathbf{1 - H i s}$ is $4.3 \times 10^{-9} \mathrm{~S} \mathrm{~cm}^{-1}$ at $146{ }^{\circ} \mathrm{C}$, while 1 shows no conductivity in the region $30-200{ }^{\circ} \mathrm{C}$. Although the observed conductivity is not high, the ionconductive range of temperatures is largely shifted from $40-80{ }^{\circ} \mathrm{C}$ to $120-146{ }^{\circ} \mathrm{C}$ compared with the bulk histamine. This increasing 40 ion-conductive temperature is attributed to the PSM treatment of the framework. Whereas the imidazole rings of histamines are assembled in the centre of the 1D pores, which is proposed from SSNMR and calculation, the conductivity is not high compared with a previous report ${ }^{9 \mathrm{a}}$ even if histamine is actually more 45 disordered than the proposed structure. We need to understand why the proton conductivity is not large even though the histamine is well packed in the pores.

We therefore carried out ${ }^{15} \mathrm{~N}$ cross-polarization magic angle spinning (CPMAS) measurements, where the chemical shift is 50 sensitive to the protonation of the nitrogen atom. ${ }^{13}$ Fig. 3 shows the natural abundance ${ }^{15} \mathrm{~N}$ CPMAS spectra of bulk histamine and 1-His at $298 \mathrm{~K}$. Compared with the spectrum of bulk histamine, the peak of alkyl amine is shifted upfield (ca. -14 ppm). This upfield shift would suggests that there is no protonation of the 55 alkyl amine ${ }^{14}$ and the amine coordinates to the metal site. ${ }^{15}$ Moreover, the peaks corresponding to the imidazole ring also change. If there was protonation of $\mathrm{N}(1)$, one coalescent peak of $\mathrm{N}(1)$ and $\mathrm{N}(2)$ would appear. However, two peaks are observed at 176 and $207 \mathrm{ppm}$ in the spectrum. Even in the variable ${ }_{60}$ temperature ${ }^{15} \mathrm{~N}$ CPMAS spectra, the peaks remain unchanged, as shown in Fig. S5. Therefore, fast proton exchange $\left(>10^{3} \mathrm{~Hz}\right)$ would not occur in the nitrogens of the imidazole ring in grafted
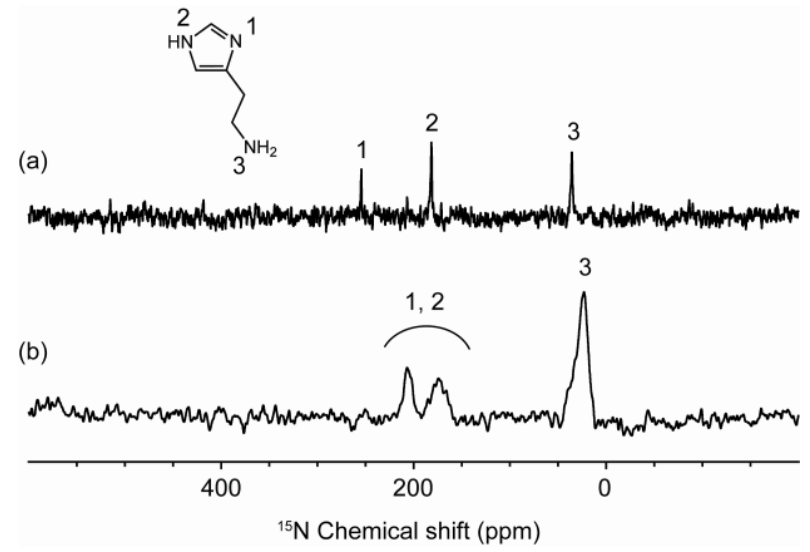
histamine.

Fig. $3{ }^{15}$ N CPMAS spectra of (a) bulk histamine and (b)1-His at $298 \mathrm{~K}$.

To elucidate the mechanism of slow proton hopping, variabletemperature ${ }^{1} \mathrm{H}$ MAS NMR of 1-His (Fig. S6) was performed. ${ }_{5}$ The peaks of histamine in the spectrum are broader and remain unchanged in the region of $25-110{ }^{\circ} \mathrm{C}$. This indicates that the mobility of histamine is lower than that of histamine in previous high proton-conducting PCP. ${ }^{9 a}$ Therefore, the low mobility of histamine in 1-His limits the proton hopping between imidazole 10 rings, thus causing low proton conductivity in the pores in spite of increasing conductive-temperature. To design proton conductors that show high conductivity at higher temperatures, we should anchor proton carrier molecules with high mobility to pore surfaces. Note that ${ }^{15} \mathrm{~N}$ and ${ }^{1} \mathrm{H}$ SSNMR studies show the 15 mechanism of proton hopping and offer suggestions for developing well-designed proton-conducting PCPs/MOFs.

In conclusion, we have elucidated the configuration, protonic state, and mobility of post-modified histamine inside pores and discussed the relation between these characterizations of 20 histamine and proton conductivity. The SSNMR studies, with the aid of calculation, show a way to characterize post-grafted substituent groups in functionalized frameworks. In addition, this study shows the first example of the synthesis of an anhydrous proton-conducting framework using PSM. This approach should 25 contribute to the study of increasing the operating temperature of anhydrous ion-conducting frameworks.

This work was supported by the Japan Science and Technology Agency PRESTO Program, Grants-in-Aid for Scientific Research, the Japan Society for the Promotion of ${ }_{30}$ Science (JSPS). iCeMS is supported by the World Premier International Research Center Initiative (WPI), MEXT, Japan.

\section{Notes and references}

${ }^{a}$ Institute for Integrated Cell-Material Sciences (WPI-iCeMS), Kyoto University, Yoshida, Sakyo-ku, Kyoto 606-8501, Japan

${ }_{35}{ }^{b}$ Department of Synthetic Chemistry and Biological Chemistry, Graduate School of Engineering, Kyoto University, Katsura, Nishikyo-ku, Kyoto 615-8510, Japan

c Japan Science and Technology Agency, PRESTO, 4-1-8 Honcho, Kawaguchi, Saitama 332-0012, Japan

${ }_{40}{ }^{d}$ Japan Science and Technology Agency, ERATO, Kitagawa Integrated Pores Project, Kyoto Research Park Bldg \#3, Shi-mogyo-ku, Kyoto 6008815, Japan

$\dagger$ Electronic Supplementary Information (ESI) available: Synthesis 45 method, calculation details, XRD patterns, TGA profile, liquid-state ${ }^{1} \mathrm{H}$ NMR spectrum, variable temperature solid-state ${ }^{15} \mathrm{~N}$ and ${ }^{1} \mathrm{H}$ spectra, and impedance measurements. See DOI: 10.1039/b000000x/

1. (a) B. Wang, A. P. Cote, H. Furukawa, M. O'Keeffe, O. M. Yaghi, 50 Nature, 2008, 453, 207; (b) J.-R. Li, R. J. Kuppler, H.-C. Zhou, Chem. Soc. Rev., 2009, 38, 1477; (c) T. Fukushima, S. Horike, Y. Inubushi, K. Nakagawa, Y. Kubota, M. Takata, S. Kitagawa, Angew. Chem., Int. Ed., 2010, 49, 4820; (d) E. Q. Procopio, F. Linares, C. Montoro, V. Colombo, A. Maspero, E. Barea, J. A. R. Navarro, Angew. Chem., Int. Ed., 2010, 49, 7308; (e) F. Vermoortele, M. Maes, P. Z. Moghadam, M. J. Lennox, F. Ragon, M. Boulhout, S. Biswas, K. G. M. Laurier, I. Beurroies, R. Denoyel, M. Roeffaers, N. Stock, T. Düren, C. Serre, D. E. De Vos, J. Am. Chem. Soc., 2011, $133,18526$.

60 2. (a) J. S. Seo, D. Whang, H. Lee, S. I. Jun, J. Oh, Y. J. Jeon, K. Kim, Nature, 2000, 404, 982; (b) A. Henschel, K. Gedrich, R. Kraehnert, S.
Kaskel, Chem. Comm., 2008, 4192; (c) S. Horike, M. Dinca, K. Tamaki, J. R. Long, J. Am. Chem. Soc., 2008, 130, 5854; (d) J. Lee, O. K. Farha, J. Roberts, K. A. Scheidt, S. T. Nguyen, J. T. Hupp, Chem. Soc. Rev., 2009, 38, 1450.

3. (a) S. Bureekaew, S. Horike, M. Higuchi, M. Mizuno, T. Kawamura, D. Tanaka, N. Yanai, S. Kitagawa, Nat Mater, 2009, 8, 831; (b) J. A. Hurd, R. Vaidhyanathan, V. Thangadurai, C. I. Ratcliffe, I. L. Moudrakovski, G. K. H. Shimizu, Nat Chem, 2009, 1, 705; (c) A. 70 Shigematsu, T. Yamada, H. Kitagawa, J. Am. Chem. Soc., 2011, 133, 2034; (d) B. M. Wiers, M. L. Foo, N. P. Balsara, J. R. Long, J. Am. Chem. Soc., 2011, 133, 14522.

4. (a) Z. Q. Wang, S. M. Cohen, J. Am. Chem. Soc., 2007, 129, 12368; (b) Z. Q. Wang, S. M. Cohen, Chem. Soc. Rev., 2009, 38, 1315; (c) S. M. Cohen, Chem. Rev., 2012, 112, 970.

5. (a) Y. K. Hwang, D. Y. Hong, J. S. Chang, S. H. Jhung, Y. K. Seo, J. Kim, A. Vimont, M. Daturi, C. Serre, G. Ferey, Angew. Chem., Int. Ed., 2008, 47, 4144; (b) A. Demessence, D. M. D'Alessandro, M. L. Foo, J. R. Long, J. Am. Chem. Soc., 2009, 131, 8784; (c) K. L. 80 Mulfort, O. K. Farha, C. L. Stern, A. A. Sarjeant, J. T. Hupp, J. Am. Chem. Soc., 2009, 131, 3866; (d) J. G. Nguyen, S. M. Cohen, J. Am. Chem. Soc., 2010, 132, 4560; (e) K. K. Tanabe, S. M. Cohen, Chem. Soc. Rev., 2011, 40, 498.

6. C. K. Brozek, M. Dinca, Chem. Sci., 2012, 3, 2110.

85 7. T. Uemura, S. Horike, K. Kitagawa, M. Mizuno, K. Endo, S. Bracco, A. Comotti, P. Sozzani, M. Nagaoka, S. Kitagawa, J. Am. Chem. Soc., 2008, 130, 6781.

8. (a) T. Ahnfeldt, D. Gunzelmann, T. Loiseau, D. Hirsemann, J. Senker, G. Ferey, N. Stock, Inorg. Chem., 2009, 48, 3057; (b) W. Morris, C. J. 90 Doonan, O. M. Yaghi, Inorg. Chem., 2011, 50, 6853.

9. (a) D. Umeyama, S. Horike, M. Inukai, Y. Hijikata, S. Kitagawa, Angew. Chem., Int. Ed., 2011, 50, 11706; (b) S. Horike, D. Umeyama, M. Inukai, T. Itakura, S. Kitagawa, J. Am. Chem. Soc., 2012, 134, 7612; (c) D. Umeyama, S. Horike, M. Inukai, T. Itakura, S. Kitagawa, J. Am. Chem. Soc., 2012, 134, 12780.

10. (a) N. L. Rosi, J. Kim, M. Eddaoudi, B. L. Chen, M. O'Keeffe, O. M. Yaghi, J. Am. Chem. Soc., 2005, 127, 1504; (b) P. D. C. Dietzel, R. E. Johnsen, R. Blom, H. Fjellvag, Chem. Eur. J., 2008, 14, 2389.

11. (a) P. Caravatti, L. Braunschweiler, R. R. Ernst, Chem. Phys. Lett., 1983, 100, 305; (b) B. J. van Rossum, H. Forster, H. J. M. de Groot, J. Magn. Reson., 1997, 124, 516.

12. S. Bracco, A. Comotti, L. Ferretti, P. Sozzani, J. Am. Chem. Soc., 2011, 133, 8982 .

13. (a) H. H. Limbach, J. Hennig, R. Kendrick, C. S. Yannoni, J. Am. 105 Chem. Soc., 1984, 106, 4059; (b) F. Aguilar-Parrilla, G. Scherer, H. H. Limbach, M. D. C. Foces-foces, F. H. Cano, J. A. S. Smith, C. Toiron, J. Elguero, J. Am. Chem. Soc., 1992, 114, 9657; (c) R. Marek, A. Lycka, E. Kolehmainen, E. Sievaenen, J. Tousek, Curr. Org. Chem., 2007, 11, 1154.

110 14. A. P. Mazurek, J. C. Dobrowolski, J. Sadlej, J. Mol. Struct., 1997, $437,435$.

15. E. Szlyk, L. Pazderski, I. Lakomska, A. Wojtczak, L. Kozerski, J. Sitkowski, B. Kamienski, H. Gunther, Polyhedron, 2003, 22, 391. 